\title{
Role of Melatonin Supplementation on Inflammatory and Oxidative Stress Markers in Critically III Patients
}

\author{
Naseh Pahlavani ${ }^{1 *}$, Seyedeh Shabnam Mazloumi Kiapey ${ }^{1}$, Safieh Firouzi ${ }^{1}$, Mahsa Malekahmadi ${ }^{1}$ \\ ${ }^{1}$ Department of Nutrition, Faculty of Medicine, Mashhad University of Medical Sciences, Mashhad, Iran
}

Corresponding Author: Naseh Pahlavani, PhD Candidate, Department of Nutrition, Faculty of Medicine, Mashhad University of Medical Sciences, Mashhad, Iran. Tel: +98-9376081205, Email: PahlavaniN951@mums.ac.ir

Received September 6, 2018; Accepted November 16, 2018; Online Published December, 27, 2018

\begin{abstract}
Critically ill patients are diagnosed with signs such as oxidative stress, mitochondrial function impairment, dysfunction of the immune system, and acute inflammation. Inflammation and oxidative stress play a major role in the pathogenicity of most diseases in patients, especially those in intensive care units. Because of the side effects of chemical anti-inflammatory drugs, which include large intestinal ulcers, bleeding, and perforation, it seems that the use of natural anti-inflammatory compounds like melatonin could be very helpful. Melatonin productively interacts with different receptive nitrogen and oxygen species (receptor autonomous activities), up-regulates antioxidant chemicals, and down-regulates pro-oxidant chemicals (receptor-dependent activities). Melatonin attenuates molecular and cellular damage resulting from inflammation and oxidative stress. Previous studies have shown that melatonin reduces inflammation and oxidative stress levels. Thus, the use of safe doses of melatonin can reduce inflammation and oxidative stress. However, further studies are needed to verify these results.

Keywords: Inflammation Mediators, Oxidative Stress, Melatonin, Intensive Care Unit, Inpatients

Citation: Pahlavani N, Mazloumi Kiapey SS, Firouzi S, Malekahmadi M. Role of Melatonin supplementation on inflammatory and oxidative stress markers in critically ill patients. Int J Med Rev. 2018;5(4):x-x. doi:10.29252/IJMR-050403.
\end{abstract}

\section{Introduction}

Inflammation is caused by the release of chemical intermediates in affected tissue and causes edema and the excretion of proteins and water outside the damaged cell at the site of inflammation. ${ }^{1}$ Critically ill patients are diagnosed with signs such as oxidative stress, mitochondrial function impairment, dysfunction of the immune system, and acute inflammation and should be admitted to an intensive care unit. ${ }^{2}$ Systemic inflammatory response syndrome is a clinical response to inflammatory or traumatic stimuli. After injury, pro-inflammatory cytokines such as interleukin 1 and 6 and tumor necrosis factor alpha (TNF- $\alpha$ ) are released. ${ }^{3}$ If the origin of this syndrome is infectious, it can lead to sepsis and, ultimately, septic shock, which is one of the main causes of mortality in patients admitted to intensive care units. ${ }^{4}$ Antibiotics and anti-inflammatory drugs are used to treat infections and inflammation in hospitalized patients, but these drugs alone cannot achieve a cure. Moreover, they have side effects. ${ }^{5,6}$ Because of the side effects of chemical antiinflammatory drugs, finding solutions to reduce inflammation in patients admitted to intensive care units can be helpful and reduce mortality in these patients. ${ }^{7,8}$

Melatonin is a hormone secreted in small amounts by the pituitary gland and has been shown in previous studies to have anti-inflammatory effects. ${ }^{9,} 10$ The purpose of this mini- review is to evaluate the effects of melatonin on reducing inflammation and oxidative stress in critically ill patients.

\begin{abstract}
Melatonin Features
The hormone melatonin is found naturally within the body. It is also utilized as a medication which ordinarily is made artificially in a research facility. This hormone is essentially secreted by the pineal organ and controls sleep-wake cycles. ${ }^{11}$ Information about melatonin has only recently come to light, starting in 1958 when Aaron Lerner discovered it in mammals, and then in 1981 when Alfred Lewy revealed that bright light affected it. ${ }^{12}$ Within the human body, melatonin levels change during the daily cycle. It has a chemical formula of $\mathrm{C} 13 \mathrm{H} 16 \mathrm{~N} 2 \mathrm{O} 2$ and a molecular mass of $232.278 \mathrm{~g} / \mathrm{mol}^{13}$ and plays a role in the regulation of the circadian rhythm of several biological functions. ${ }^{14}$ Figure 1 shows the chemical structure of melatonin.
\end{abstract}

\section{Role of Inflammation and Oxidative Stress}

Inflammation is a defensive reaction against tissue and cell damage. Reactive oxygen species (ROS), such as the superoxide anion freed by phagocytes and recruited into inflamed sites, are proposed to be a major cause of cell and tissue damage..$^{15,16}$ In the process of inflammation, pro-inflammatory cytokines affect the production of T-cells, monocytes, neutrophils,

Copyright (C) 2018 The Author(s). This is an open-access article distributed under the terms of the Creative Commons Attribution License (http:// creativecommons.org/licenses/by/4.0), which permits unrestricted use, distribution, and reproduction in any medium, provided the original work is properly cited. 


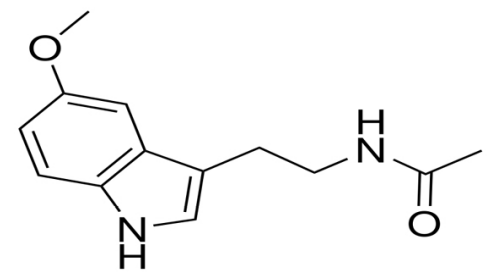

Figure 1. Chemical Structure of Melatonin.

endothelial cells, and leptin. Moreover, they have a direct effect on macrophages, and increase the activity of phagocytosis. By increasing the level of leptin, the $\mathrm{C}$ reactive protein is produced and causes inflammatory effects. ${ }^{17}$ TNF- $\alpha$ is secreted mainly by lymphocytes, adipose tissue, muscle, and monocytes. It was one of the first cytokines to be identified and is involved in systemic inflammatory responses. ${ }^{18,19}$ Interleukin 6 (IL-6), produced by macrophages and adipocytes, is a cytokine that exerts many effects ranging from defense to inflammation and organ damage. ${ }^{20,21}$ The discharge of cytokines/chemokines actuates neutrophil recruitment and key transcription factors such as nuclear factor-kB (NF-kB) and activator protein-1 (AP-1), increasing the inflammatory reaction and tissue harm..$^{22}$ Mitochondria, cytochrome $\mathrm{P} 450$, and peroxisome are the main sources of reactive species in all cells. Under physiological situations, there is a steady endogenous output of reactive nitrogen intermediate (RNI) and reactive oxygen intermediate (ROI) that interact as "signaling" molecules for metabolism, cell cycle, and intercellular transduction pathways. ${ }^{23}$ Therefore, controlling the conditions of inflammation and oxidative stress can help patients improve faster. The pathophysiology of inflammation and oxidative stress are shown in Figure 2.

\section{Role of Melatonin in Inflammation and Oxidative Stress}

Though initially thought to be produced exclusively in the pineal gland, melatonin (N-acetyl-5-methoxytryptamine) secretion has been found in other organs, such as the retina, bone marrow, and bile. ${ }^{24}$ High levels of melatonin have not been found in these organs, but its secretion is not confined to the pineal gland and has been shown to lead to anti-inflammatory effects through several pathways. ${ }^{24}$ It is an established fact that the endocrine and nervous systems can interact with the immune system in order to modulate its function ${ }^{25}$; many hormones, neuroendocrine factors, and neurotransmitters can actually improve the function of the immune system. ${ }^{26}$ Melatonin is also able to improve immune situations through its neuroendocrine function. It acts as a regulator of circadian rhythms ${ }^{26,27}$ in a hormone-like mold by influencing target cells and balancing other capacities depending on the photoperiod counting control of photoperiodic motions of the immune/ inflammatory reaction. ${ }^{28}$ Alamili et al showed that melatonin administration in sepsis patients can reduce the levels of proinflammatory markers such as IL- $1 \beta .{ }^{29}$ In one animal study, the use of melatonin in mice with septic shock at a dose of $10 \mathrm{mg} / \mathrm{kg}$ twice daily for 3 days reduced pro-inflammatory factors of TNF- $\alpha$ and IL- $6 .{ }^{30}$ In another study, melatonin at a dose of $20 \mathrm{mg} / \mathrm{d}$ for 72 days in neonates with septic shock reduced the levels of C-reactive protein, white blood cells, and

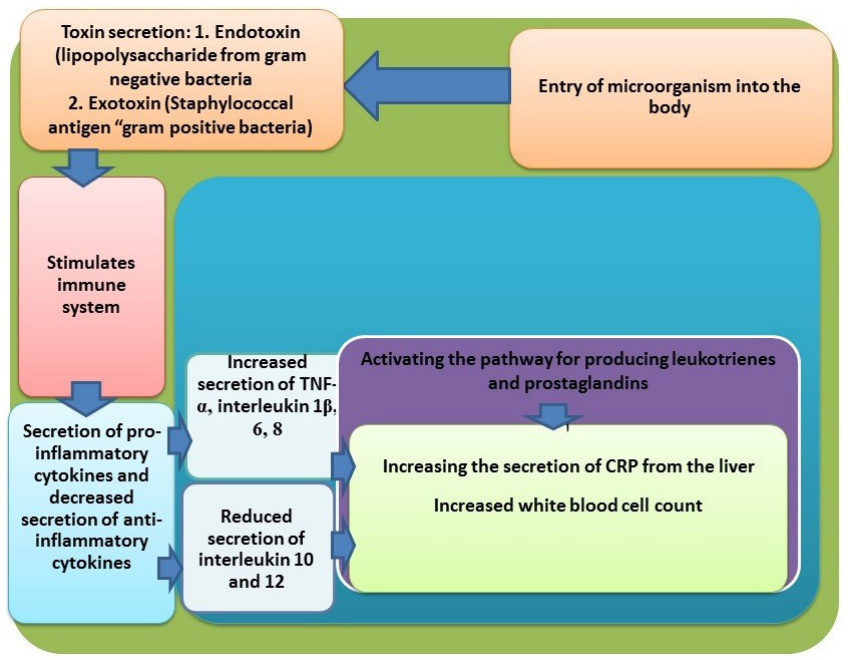

Figure 2. Pathophysiology of Inflammation and Oxidative Stress.

lipid peroxidation, and ultimately reduced infant mortality. ${ }^{31}$ Gitto et al reported that supplementation with $10 \mathrm{mg} / \mathrm{kg}$ of body weight of melatonin for 7 days in newborns with respiratory distress syndrome decreased lipid peroxidation, reduced nitrite and nitrate levels, and decreased TNF- $\alpha$ and interleukin 6 and 8 levels. ${ }^{32}$ Therefore, it seems that melatonin has had a positive effect on the reduction of inflammation and oxidative stress in previous studies, but these effects have not yet been fully proven.

\section{Conclusions}

Inflammation and oxidative stress are major factors in reducing the recovery rate and increasing mortality among critically ill patients hospitalized in intensive care units. Studies have shown that the use of melatonin in safe doses can reduce the rate of inflammation and oxidative stress and ultimately reduce the rate of mortality, but more clinical trials are needed to confirm this result.

\section{Authors' Contributions}

All authors contributed equally to this study.

\section{Conflict of Interest Disclosures}

The authors declare they have no conflicts of interest.

\section{Acknowledgments}

The authors would like to thank Dr. Jamshid Gholizadeh Naveshenaq and all others who helped make this study possible.

\section{References}

1. Rankin JA. Biological mediators of acute inflammation. AACN Clin Issues. 2004;15(1):3-17. doi:10.1097/00044067-20040100000002.

2. Manzanares W, Dhaliwal R, Jiang X, Murch L, Heyland DK. Antioxidant micronutrients in the critically ill: a systematic review and meta-analysis. Crit Care. 2012;16(2):R66. doi:10.1186/ cc11316.

3. Talmor M, Hydo L, Barie PS. Relationship of systemic inflammatory response syndrome to organ dysfunction, length of stay, and mortality in critical surgical illness: effect of intensive care unit 
resuscitation. Arch Surg. 1999;134(1):81-87. doi:10.1001/ archsurg.134.1.81.

4. Yousef AA, Amr YM, Suliman GA. The diagnostic value of serum leptin monitoring and its correlation with tumor necrosis factoralpha in critically ill patients: a prospective observational study. Crit Care. 2010;14(2):R33. doi:10.1186/cc8911.

5. Cunha BA. Sepsis and septic shock: selection of empiric antimicrobial therapy. Crit Care Clin. 2008;24(2):313-334, ix. doi:10.1016/j.ccc.2007.12.015.

6. Schacke H, Docke WD, Asadullah K. Mechanisms involved in the side effects of glucocorticoids. Pharmacol Ther. 2002;96(1):23-43. doi:10.1016/S0163-7258(02)00297-8.

7. Walsh TS, Stanworth SJ, Prescott RJ, Lee RJ, Watson DM, Wyncoll D. Prevalence, management, and outcomes of critically ill patients with prothrombin time prolongation in United Kingdom intensive care units. Crit Care Med. 2010;38(10):1939-1946. doi:10.1097/ CCM.0b013e3181eb9d2b.

8. Suleyman H, Demircan B, Karagoz Y. Anti-inflammatory and side effects of cyclooxygenase inhibitors. Pharmacol Rep. 2007;59(3):247-258.

9. Stehle JH, Saade A, Rawashdeh O, et al. A survey of molecular details in the human pineal gland in the light of phylogeny, structure, function and chronobiological diseases. J Pineal Res. 2011;51(1):17-43. doi:10.1111/j.1600-079X.2011.00856.x.

10. Favero G, Franceschetti L, Bonomini F, Rodella LF, Rezzani R. Melatonin as an Anti-Inflammatory Agent Modulating Inflammasome Activation. Int J Endocrinol. 2017;2017:1835195. doi:10.1155/2017/1835195.

11. Hebert M, Martin SK, Lee C, Eastman Cl. The effects of prior light history on the suppression of melatonin by light in humans. J Pineal Res. 2002;33(4):198-203. doi:10.1034/j.1600079X.2002.01885.x.

12. Yu HS, Reiter RJ. Melatonin: biosynthesis, physiological effects, and clinical applications. CRC Press; 1992.

13. Reiter RJ. The mammalian pineal gland: structure and function. Am J Anat. 1981;162(4):287-313. doi:10.1002/aja.1001620402.

14. Kennaway DJ, Wright H. Melatonin and circadian rhythms. Curr Top MedChem.2002;2(2):199-209.doi:10.2174/1568026023394380.

15. Morcillo EJ, Estrela J, Cortijo J. Oxidative stress and pulmonary inflammation: pharmacological intervention with antioxidants. Pharmacol Res. 1999;40(5):393-404. doi:10.1006/ phrs.1999.0549.

16. Rahman I, Morrison D, Donaldson K, MacNee W. Systemic oxidative stress in asthma, COPD, and smokers. Am J Respir Crit Care Med. 1996;154(4 Pt 1):1055-1060. doi:10.1164/ ajrccm.154.4.8887607.

17. Steffes MW, Gross MD, Lee DH, Schreiner PJ, Jacobs DR Jr. Adiponectin, visceral fat, oxidative stress, and early macrovascular disease: the Coronary Artery Risk Development in Young Adults Study. Obesity (Silver Spring). 2006;14(2):319-326. doi:10.1038/ oby.2006.41.

18. Sanchez-Munoz F, Garcia-Macedo R, Alarcon-Aguilar F, Cruz M.
[Adipocitokines, adipose tissue and its relationship with immune system cells]. Gac Med Mex. 2005;141(6):505-512.

19. Ouchi N, Parker JL, Lugus JJ, Walsh K. Adipokines in inflammation and metabolic disease. Nat Rev Immunol. 2011;11(2):85-97. doi:10.1038/nri2921.

20. Fonseca-Alaniz MH, Takada J, Alonso-Vale MI, Lima FB. Adipose tissue as an endocrine organ: from theory to practice. J Pediatr (Rio J). 2007;83(5 Suppl):S192-203. doi:10.2223/jped.1709.

21. Fernandez-Sanchez A, Madrigal-Santillan E, Bautista M, et al. Inflammation, oxidative stress, and obesity. Int J Mol Sci. 2011;12(5):3117-3132. doi:10.3390/ijms12053117.

22. Rahman I, MacNee W. Oxidative stress and regulation of glutathione in lung inflammation. Eur Respir J. 2000;16(3):534554. doi:10.1034/j.1399-3003.2000.016003534.x.

23. Nathan C. Specificity of a third kind: reactive oxygen and nitrogen intermediates in cell signaling. J Clin Invest. 2003;111(6):769-778. doi:10.1172/jci18174.

24. Reiter RJ, Calvo JR, Karbownik M, Qi W, Tan DX. Melatonin and its relation to the immune system and inflammation. Ann $\mathrm{N} \mathrm{Y}$ Acad Sci. 2000;917(1):376-386. doi:10.1111/j.1749-6632.2000. tb05402.x.

25. Blalock JE. The syntax of immune-neuroendocrine communication. Immunol Today. 1994;15(11):504-511. doi:10.1016/01675699(94)90205-4.

26. Ader R, Cohen N, Felten D. Psychoneuroimmunology: interactions between the nervous system and the immune system. Lancet. 1995;345(8942):99-103. doi:10.5555/ uri:pii:S0140673695900667.

27. Radogna F, Diederich M, Ghibelli L. Melatonin: a pleiotropic molecule regulating inflammation. Biochem Pharmacol. 2010;80(12):1844-1852. doi:10.1016/j.bcp.2010.07.041.

28. Scheff JD, Calvano SE, Lowry SF, Androulakis IP. Modeling the influence of circadian rhythms on the acute inflammatory response. J Theor Biol. 2010;264(3):1068-1076. doi:10.1016/j. jtbi.2010.03.026.

29. Alamili M, Bendtzen K, Lykkesfeldt J, Rosenberg J, Gogenur I. Melatonin suppresses markers of inflammation and oxidative damage in a human daytime endotoxemia model. J Crit Care. 2014;29(1):184.e189-184.e113. doi:10.1016/j.jcrc.2013.09.006.

30. Carrillo-Vico A, Lardone PJ, Naji L, et al. Beneficial pleiotropic actions of melatonin in an experimental model of septic shock in mice: regulation of pro-/anti-inflammatory cytokine network, protection against oxidative damage and anti-apoptotic effects. J Pineal Res. 2005;39(4):400-408. doi:10.1111/j.1600079X.2005.00265.x.

31. Gitto E, Karbownik M, Reiter RJ, et al. Effects of melatonin treatment in septic newborns. Pediatr Res. 2001;50(6):756-760. doi:10.1203/00006450-200112000-00021.

32. Gitto E, Romeo C, Reiter RJ, et al. Melatonin reduces oxidative stress in surgical neonates. J Pediatr Surg. 2004;39(2):184-189; discussion 184-189. doi:10.1016/j.jpedsurg.2003.10.003. 